\title{
Discussion on Architecture Conception
}

\author{
Shengxiao $\mathrm{Li}^{1, \mathrm{a}}$, Jun $\mathrm{Ma}^{1, \mathrm{~b}}$ and $\mathrm{Ran} \mathrm{Bi}^{2, \mathrm{c}}$ \\ ${ }^{1}$ Architectural Design and Research Institute, Shenyang Jianzhu University, Shenyang, 110168, \\ China P.R. \\ ${ }^{2}$ College of Civil Engineering, Shenyang Jianzhu University, Shenyang, 110168, China P.R. \\ alishengxiao@163.com, bwyasyn@163.com, cbiran@163.com
}

Keywords: Architectural conception, Creative, Intention, Thinking

Abstract: There will be creative intention and thinking in any architectural design. Based on some case, this paper explicates methods getting intention. Conditions--questions--are not handicap, are the condition getting valuable, significant intention. Good idea depends on good thoughts, conception is the premise of creative thinking.

\section{Introduction}

Architectural design is the creation process of the building, creation is to innovate, to be creative. Real architectural design is to have their own ideas, and should not be seen in the new architecture of a certain existing building, each building should reflect the creative ideas and the specific nature of the building, which reflects its intended function, to adapt to its geographical environment and human environment, which has its unique personality.

The idea of architectural design is the initial condition of the building's personality and thought. Architectural design ideas by conception and expression skills to achieve, is a process from emotional to rational design of.

And for the first time, it is conception, also knowns as the artistic conception which is of architect design intent general summary, the basic idea of the future construction, is the starting point of the idea, is initiated by the architect in the initial stage of design idea. The conception, put forward the question of stage.

Architectural design is in determining of the creative conception, around the intention to start the active imagination process, and is to realize the idea of implementation process. To think about how to embody the process of a spirit in the form of a substance. It can be said that the idea is to solve the problem of imagination stage. The expression of skills, in order to achieve the design conception, taken in the process of conception in specific methods. That is a solution to the problem.

\section{The Example of Building Conception}

Conception is a prerequisite for successful works in literature, painting and calligraphy, is the soul of the work. However, the process of art creation is interlinked, architectural creation is the same, the conception is very important. The conception is the embodiment of the creator's creative intention, can be said to reflect creator thought, embodies the view of life or life philosophy.The conception is the embodiment of the creator's creative intention, can be said to reflect creator thought, embodies the view of life or life philosophy.Put forward the conception is in all the given conditions, such as:

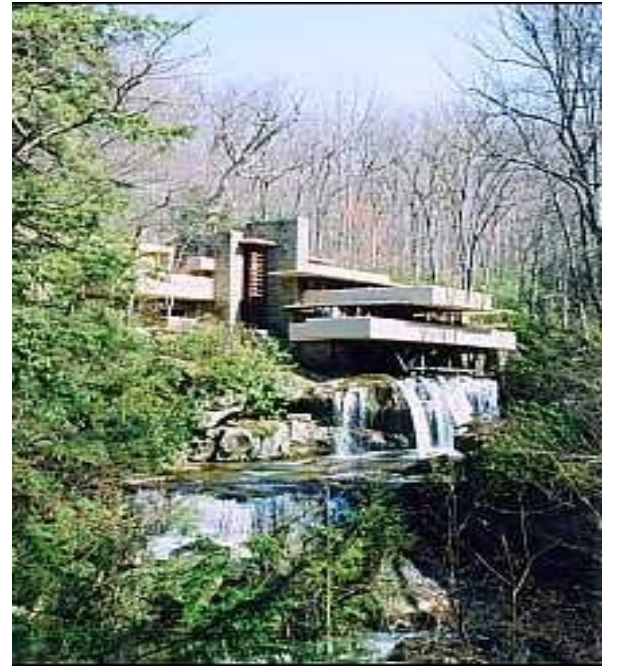

Figure1 Falling-water Villa 
nature of the building, the scale of construction, service object, base environment and so on, put forward the main problems. Bai Zuomin wrote in an article: "the architect's creative activity is from the beginning of social order, and is facing a series of objective constraints. The whole creation process is a 'controlled' process." Any of a successful design is impossible crossed the restriction, but rather to actively look for process control in, from necessity to freedom. " In the face of control, we should not complain, in contrast, these constraints are the achievements we can create a prerequisite for the work of a personality. To analyze and evaluate the existing constraints, to grasp and use the constraints, to create a building. The conception of initiative can be showed, may be a potential problem. It can be passively in order to solve some practical problems, and then have the conception. Common source is to follow, the personality is derived from creation.

The famous Falling-water (Figure 1) is an ingenious architectural art, create new styles. It works (Figure 1) water villa reflects a conception of the proposed way before. Kauffman, the owner of the original owners want to build the living room facing the waterfall. The architect Wright, according to their own thinking will be built on the top of the falls, and persuaded the Kauffman couple. Buildings outside in the environment, as is the natural growth of, and natural form an interlocking, mutual penetration of the pattern. So that artificial construction and natural scenery to each other, complement each other. This is the architect Wright initiative and the natural environment, the conception of harmonious coexistence. At the same time, it reflects the architect's creative ideas and his philosophy of life.

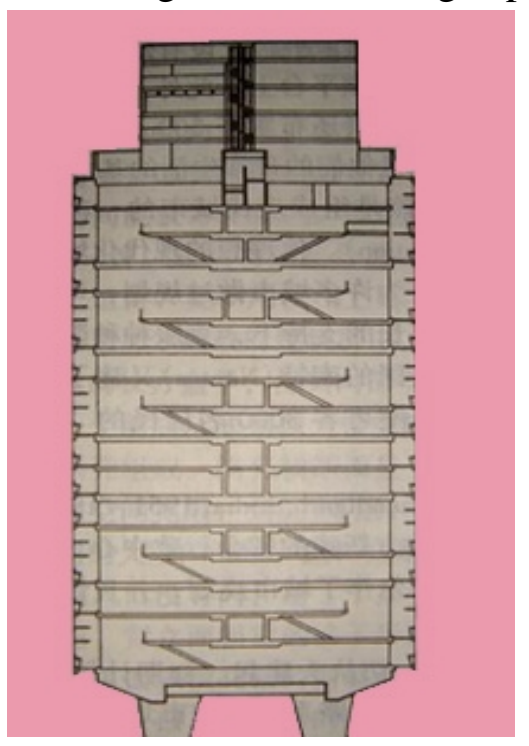

Figure 2 Standard user profile of Marseille apartment

Marseille apartment ia architect Le Corbusie for mankind to create a new mode of social life, it can

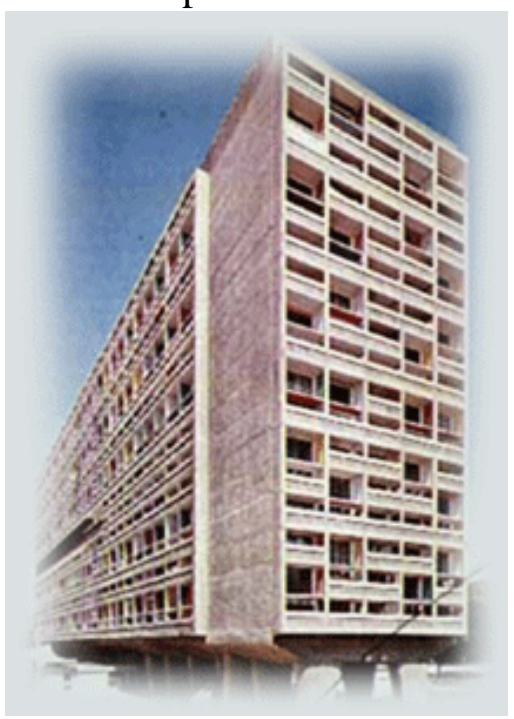

Figure3 Marseille apartments be said that the conception of Marseille apartment is great, it changes the people's life improved in the interaction between neighbors, makes residents feel where your life, not only for the individual existence, not like before such in difference, between neighbors often meet, frequent exchanges and enhance the friendship between each other. It makes the apartment is more like a harmonious family (see Figure 2). The architects of their own problems, resulting in conception, this conception is architects create boldly and great creation, is valuable and meaningful well intentioned.

Marseille apartments reflects the architect positive thoughts, negative conservative idea of architecture and architectural style,

advocates to create a new era of the new building, and shows him to the architectural design of the new five principles (see Figure 3 ) in the design, creatively proposed architects I of the architectural aesthetics point of view and formed his own aesthetic system, and thought it is not constant of has been changing in. He put forward the theory of "bright city", and depicts the advanced state of urban life. Advocated that the building is no longer lifeless, isolated existence, but with the community environment can be merged into an

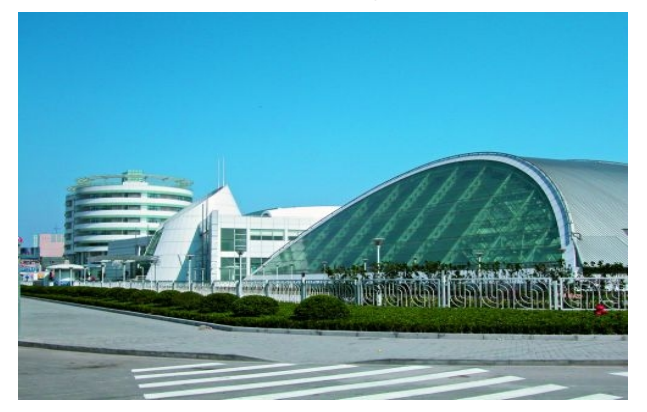

Figure 4 the Chinese disabled sports art training base 


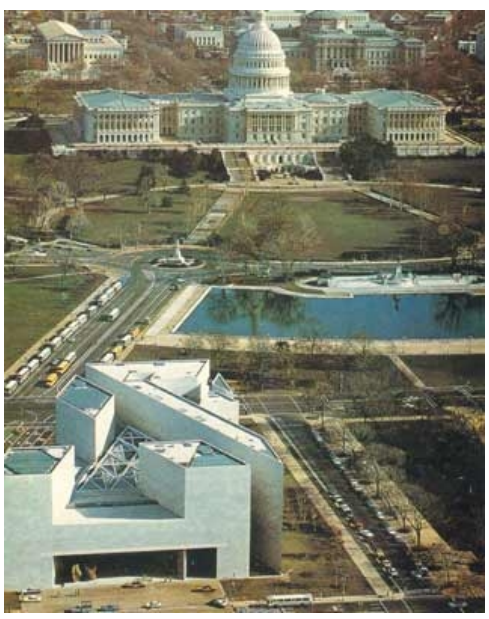

Figure5 Interior design

organism, the form of coordination, the continuation of the function and space complementary and fusion, the two are dynamic, harmonious unification. His architectural thought had a profound influence on the development of the later architecture.Therefore, architects should have a positive and active improvement of social life, and to think about and to attach to the efforts of the action.

The design of China's handicapped sports art training base (see Figure 4) to design a disabled temples and shrines, residual health sharing "as the conception, the expression of the care for the disabled. Designers in the end to watch China Disabled Art Troupe in Shanghai Grand Theatre Performance, decided to will experience the shock and the cause of the disabled to know to carry the Interior design (see Figure 5), vegetarian, elegant, out clean, pure. Here "handicapped beauty" does (Figure 4) China's handicapped sports art training base is earthshaking, but the euphemism expression of self-reliance of persons with disabilities perseverance. Embodies the simple and the pursuit of the people with disabilities: love life, love life.

The United States of America in Washington, D. C. Ieoh Ming Pei, the architect of the The National Gallery (Figure 6), is a very personal building. The use of triangular and diamond shaped mixed in the form of two of the collection in the Houses of Parliament, and can take care of the adjacent grid road. Such a flat shape does not come from the inspiration or follow one's inclinations, but from carefully solve the housing city planning, with the original to the adjacent buildings and the surrounding environment, especially with the original owners Museum. Realized the building and the terrain echo. This reflects a purposive manner after.

The success of architectural design works or not, not only to see it whether in function, visual meet people's requirements, in the body, texture fine to people to enjoy the beauty, but also

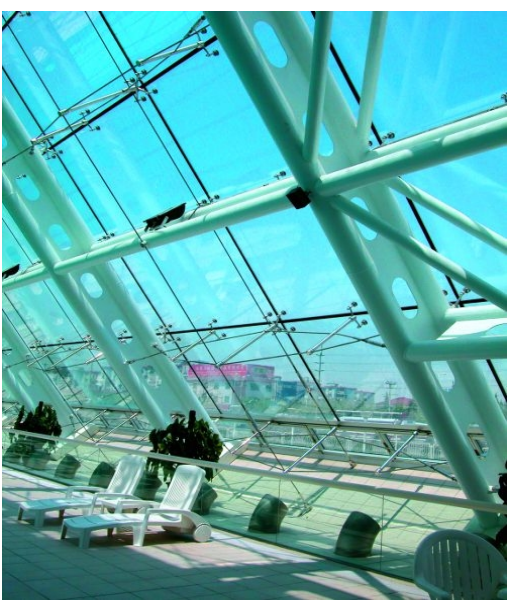

Figure6 The National Gallery East Pavilion, Washington,USA to to see whether it can reflect the spirit of the times, social phenomena and climate environment, is built building to reflect the thought. On the front building conception have vitality conception.

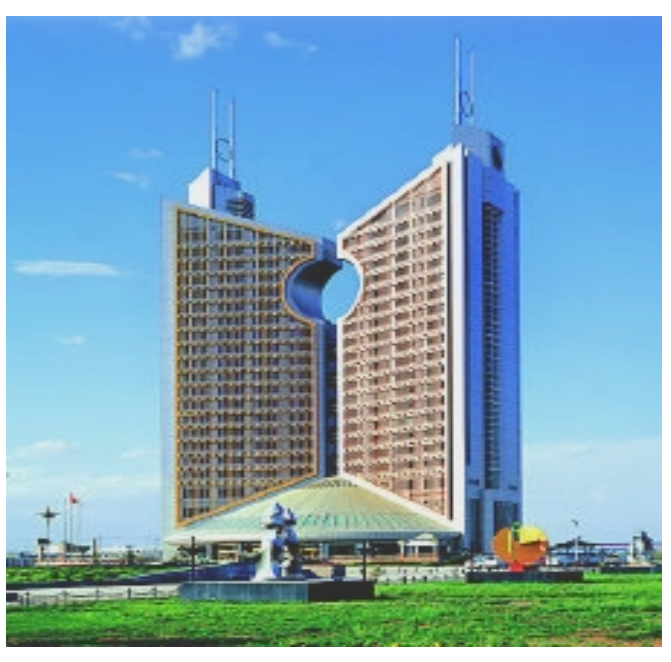

Figure7 Twenty-first Century building Therefore, the conception is the most important condition of good works.

However, nowadays, the building stands in the motherland beautiful rivers and mountains of a country and how much is a thought, the soul? Creative conception should also be suitable for geographic environment and historical context, etc., can not be put in the place you think good architecture moved here, others can not be such a conception, you can also use. This will only make the "work" of your "work", more serious may be blamed.

Walking in the streets of Shenyang City, a square box of reinforced concrete piled up, flat and tasteless to stand, let people see the first eye, do not want to see a few more. 
May occasionally find one or two impressive buildings, for example, Hunnan New District in Shenyang, the 21st century building (see Figure 7), a round hole on the facade will 21st century dawn from the back side of the building are introduced into the facade, metaphorical. And some buildings will also give a deep impression, not because of its great spirit, but because it reflects the absolute superficial. For example, Shenyang north railway station in the vicinity of a building (see Figure 8), who to hold the post of read know it expresses the meaning "money",is not can be figuratively as"mercenary" do? The lack of such a conception connotation, but also reflects the designer tocater to the owners of the money, and without a moment of hesitation made scheme. "Superficial" two words in the embodied take in everything in a glance.

\section{Conclusion}

With the continuous development of the reform and opening up, the Chinese contemporary architecture is influenced by the world's architectural culture, and the trend of globalization is obvious. At present, a lot of architectural design personnel, the traditional cultural ideas, the regional culture has no independent thinking. China's culture is profound, the construction culture is also worthy of promotion. Contemporary Chinese architecture in exploration and development, as a contemporary construction workers, each person has the responsibility to play a creative, development of their own, the local area of the building culture, local culture, and create a building with the characteristics of the national quality. This will be your gift to the local people, and it will be a successful one for the world's cultural history and architectural history.

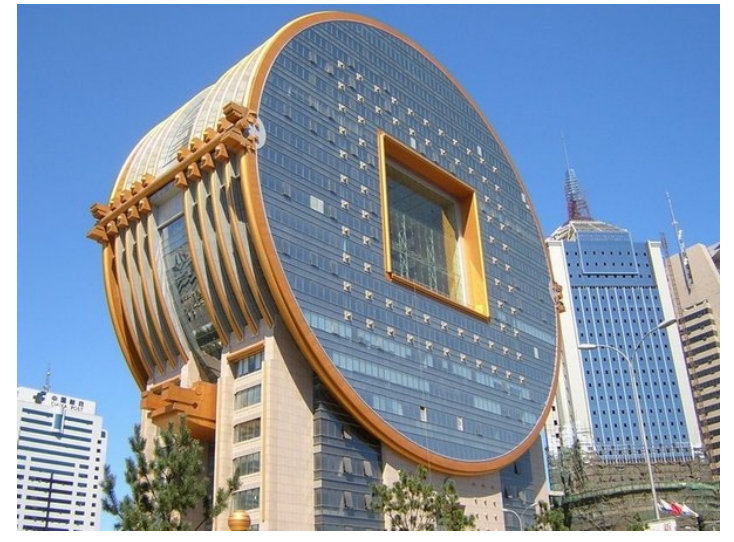

Figure8 A building near Shenyang North Railway Station

The famous architect Eero - Saarinen once said: "the building is not only to meet the needs of the people of the house, it is necessary to make people aware of survival on earth noble." Architects shoulder the important task of the times, more people's expectations. Should continue to learn, improve themselves, improve their own self-cultivation, and enhance the creation of a better environment for human social responsibility, positive thinking, the courage to explore.

Finally, citing an essay "creation" in a word, to share with you. "With your rich nature to communicate and understand people, only that you can stay away from the wither, believe that you are the only one in the world, no one can repeat your thoughts, your footprints, your emotions, this unique dedication to the world, you will enter the world's most beautiful scenery."

\section{References}

[1]Foreign modern architectural history of Tongji University / edited by Luo Xiaowei. 2. Beijing: China Architectural Industry Press, 2003

[2]In the architectural design conception and idea / Lu Jiwei. Beijing: Chinese Architectural Industry Press, 2002

[3]The construction of the meaning in the computer era of building / Liu Yudong. - Tianjin: Tianjin University press, 1999(Architecture in the Computer Era Understanding)

[4]The creation of personality building, white suketami. "Building", 1986 fifth

[5]The design conception, 5 China disabled sports art training base interior design and decoration, in 2004 third 